\title{
A case-control study of GST polymorphisms and arsenic related skin lesions
}

Kathleen M McCarty*1,2, Louise Ryan³, E Andres Houseman³, Paige L Williams ${ }^{3}$, David P Miller ${ }^{2}$, Quazi Quamruzzaman ${ }^{4}$, Mahmuder Rahman ${ }^{4}$, Golam Mahiuddin ${ }^{4}$, Thomas Smith², Ernesto Gonzalez ${ }^{5}$, Li Su${ }^{2}$ and David C Christiani ${ }^{2}$

\author{
Address: ${ }^{Y}$ Yale University School of Medicine, Epidemiology and Public Health, Division of Environmental Health Sciences, New Haven, CT, USA, \\ ${ }^{2}$ Harvard School of Public Health Department of Environmental Health, Boston, MA, USA, ${ }^{3}$ Harvard School of Public Health Department of \\ Biostatistics, Boston, MA, USA, ${ }^{4}$ Dhaka Community Hospital, Dhaka, Bangladesh and ${ }^{5}$ Massachusetts General Hospital, Boston MA, USA \\ Email: Kathleen M McCarty* - kmccarty@hohp.harvard.edu; Louise Ryan - lryan@hsph.harvard.edu; E \\ Andres Houseman - ahousema@hsph.harvard.edu; Paige L Williams - paige@hsph.harvard.edu; David P Miller - dmiller@hohp.harvard.edu; \\ Quazi Quamruzzaman - dch@bangla.net; Mahmuder Rahman - dch@bangla.net; Golam Mahiuddin - dch@bangla.net; \\ Thomas Smith - tsmith@hohp.harvard.edu; Ernesto Gonzalez - egonzalez1@partners.org; Li Su - lisu@hohp.harvard.edu; \\ David C Christiani - dchristi@hsph.harvard.edu \\ * Corresponding author
}

Published: 6 February 2007

Environmental Health 2007, 6:5 doi:10.1186/1476-069X-6-5

This article is available from: http://www.ehjournal.net/content/6/1/5

(C) 2007 McCarty et al; licensee BioMed Central Ltd.

This is an Open Access article distributed under the terms of the Creative Commons Attribution License (http://creativecommons.org/licenses/by/2.0), which permits unrestricted use, distribution, and reproduction in any medium, provided the original work is properly cited.

\begin{abstract}
Background: Polymorphisms in GSTTI, GSTMI and GSTPI impact detoxification of carcinogens by GSTs and have been reported to increase susceptibility to environmentally related health outcomes. Individual factors in arsenic biotransformation may influence disease susceptibility. GST activity is involved in the metabolism of endogenous and exogenous compounds, including catalyzing the formation of arsenic-GSH conjugates.
\end{abstract}

Methods: We investigated whether polymorphisms in GSTTI, GSTPI and GSTMI were associated with risk of skin lesions and whether these polymorphisms modify the relationship between drinking water arsenic exposure and skin lesions in a case control study of I 200 subjects frequency matched on age and gender in community clinics in Pabna, Bangladesh in 200I-2002.

Results and discussion: GSTTI homozygous wildtype status was associated with increased odds of skin lesions compared to the null status (ORI.56 95\% Cl I.10-2.19). The GSTPI GG polymorphism was associated with greater odds of skin lesions compared to GSTPI AA, (OR I.86 (95\% CI I.15-3.00). No evidence of effect modification by GSTTI, GSTM I or GSTPI polymorphisms on the association between arsenic exposure and skin lesions was detected.

Conclusion: GSTTI wildtype and GSTPI GG are associated with increased risk of skin lesions.

\section{Background}

Arsenic exposure through drinking water is a global problem, and has reached crisis status in Bangladesh [1-5]. A well established exposure-response relationship exists between arsenic level of drinking water and skin 
lesions[6,7]. Skin lesions are considered one of the most distinctive endpoints of chronic arsenic exposure[8].

It has been proposed that there are differences in susceptibility to arsenic due to individual genetic variability in biotransformation of the metal[9]. Polymorphisms in GST genes have been associated with susceptibility to a range of diseases, and GST polymorphisms alone and in concert with environmental exposures are associated with disease outcomes and behavior of several enzymes [1012]. Glutathione S-transferases (GST) are a superfamily of enzymes that are key in the detoxification step of Phase II metabolism, usually by catalyzing the conjugation of reduced glutathione (GSH) into hydrophobic and electrophilic compounds along with other Phase II enzymes [10-12]. In vivo studies have shown that GSH serves as a reducing agent required for the reduction of arsenate to arsenite[13]. GSH also serves as a reducing agent in the methylation of arsenic from arsenite to MMM (V) and from MMA (III) to DMA (V) [13]. GST activity is involved in the metabolism of endogenous and exogenous compounds, including catalyzing the formation of arsenicGSH conjugates[13,14]. Animal data had demonstrated that these conjugates are transported by multidrug resistant protein transporters (MRP) from the liver to the bile [14-17]. Glutathione and related enzymes are also involved in cellular protection against reactive oxygen species (ROS) [11,12]. Chronic arsenic exposure has been shown to alter glutathione metabolism and cellular redox status and maintenance of cellular redox state may have an important role in arsenic related pathology $[14,18,19]$.

The biologic control of GST enzymes is multifaceted in that they demonstrate specific patterns of expression that depend on sex, age, tissue, and species and vary between individuals $[11,20]$. GSTM1, GSTT1 and GSTP1 are members of the Mu $(\mu)$, Theta $(\theta)$, and Pi $(\pi)$ classes respectively[10]. Polymorphisms in GSTT1, GSTM1 and GSTP1 alone or in concert with environmental exposures may be associated with increased susceptibility to environmentally related diseases such as cancer and other clinical outcomes[10,12]. The GSTT1 null and GSTM1 null genotypes are deletion polymorphisms and have no $\theta$ or $\mu$-glutathione $S$ transferase activity respectively. The GSTP1 polymorphism is a single base pair substitution where adenine is replaced by guanine resulting in an amino acid change in which isoleucine $\left(\mathrm{I}_{105}\right)$ is replaced by valine $\left(\mathrm{V}_{105}\right)$, possibly resulting in lower enzyme activity $[21,22]$. At higher arsenic exposure, increased GST activity may be associated with saturation of MRP transporters allowing increased tissue accumulation[14]. We hypothesized that elevated glutathione-S-transferase activity, specifically activity of glutathione- $\mu, \theta$, and $\pi$ transferases, may be associated with increased risk of skin lesions.
We investigated the relationship between GSTT1, GSTM1, and GSTP1 polymorphisms and skin lesions. In addition, we assessed possible effect-modification by GST genotypes in modifying the risk of arsenic related skin lesions using well water arsenic concentration to estimate exposure.

\section{Methods Study population}

This study was conducted in the Pabna district of Bangladesh, located north of Dhaka on the Pabna (Ganges) River. Pabna was chosen for the following reasons: elevated arsenic was suspected in some of the region's villages due to proximity to the River; Dhaka Community Hospital (DCH) has a well established clinic network in the area; and Pabna is representative of socioeconomic status of much of non-urban Bangladesh. Eligible cases were Pabna residents, at least 16 years of age, with one or more type of skin lesion: diffuse/spotted melanosis, diffuse/spotted keratosis, hyperkeratosis, or leukomelanosis. One physician made the diagnosis, and treatment was provided at DCH when necessary. Controls were healthy individuals diagnosed as free of skin lesions and arsenic related disease randomly selected in a 1:1 ratio from Pabna, age of at least 16 years, living in the same village as cases but not sharing a tube well. Controls were also frequency matched to cases based on gender and age (+/- 3 years). To ensure heterogeneity of exposure and to prevent overmatching on exposure, controls were further selected so as to ensure that $80 \%$ were in "low-exposure" arsenic $(<50 \mu \mathrm{g} / \mathrm{l})$ communities and 20\% were from suspected "high exposure" ( $\geq 50 \mu \mathrm{g} / \mathrm{l})$ areas. This last ensured that the exposure distribution among controls matched that which has been reported for the Pabna region as a whole[23].

Initial measurements of well arsenic levels were made with Merck field test kits[24]. Individuals found to have arsenic exposure greater than $50 \mu \mathrm{g} / \mathrm{l}$ were advised of alternative drinking water sources. The participation rate was 98.0\%; a total of 24 subjects from 1224 declined to participate. Cases and controls had similar reasons for refusal. The population is ethnically homogenous, and similar to the population of Bangla (West Bengal), India. Informed consent was obtained from all study participants. The study protocol was approved by the Institutional Review Boards at Dhaka Community Hospital, Bangladesh and Harvard School of Public Health Boston, MA, USA.

\section{Interviews and sample collection}

In 2001-2002, 1200 subjects were recruited. Physicians, blinded to exposure status, examined potential cases and controls. Trained interviewers administered the questionnaire regarding exposure, lifestyle factors, and collected individual well water samples. Data were collected on lit- 
ers of water/liquid ingested per day, disease history, residential history including identification of the primary water source (tube well), years of use, and use of a previous tube well.

Collection of well water samples was designed to minimize bias. Due to the fact that "high" exposure ( $\geq 50 \mu \mathrm{gAs} /$ l) wells were often painted red and "low" exposure wells $(<50 \mu \mathrm{gAs} / \mathrm{l})$ were often painted green, the field team would have known if they had some indication as to whether the well was above or below $50 \mu \mathrm{g}$ As/l. However, the field team did not know the arsenic concentration of the well at the time the subject was examined and interviewed, a procedure similar to a study in West Bengal [25].

Additionally, it has been documented that wells are often mislabeled[26]. Thus, the field team was blind to the true exposure level of the subjects at the time case status was determined. Water samples were analyzed in the United States and the field team received results after subjects were enrolled.

Upon collection of each $100 \mathrm{ml}$ water sample two drops $(0.2 \mathrm{ml})$ of pure nitric acid was added. The samples were stored in a cooler before storage in a $4{ }^{\circ} \mathrm{C}$ refrigerated room. Analysis of each sample for arsenic concentration was completed using Environmental Protection Agency (EPA) method 200.8 with Inductively Coupled Plasma Mass Spectroscopy (ICP-MS) (Environmental Laboratory Services, North Syracuse, New York)[27]. The method limit of detection was $1 \mu \mathrm{g}$ As/l.

Two $10 \mathrm{ml}$ EDTA tubes were used to collect blood and were stored in a cooler on ice until processed with cell lysis solution. Samples were sent to the Molecular Epidemiology Laboratory at Harvard School of Public Health for DNA extraction and genotyping.

\section{Genotyping}

DNA samples were stored at $-80^{\circ} \mathrm{C}$. The GSTM1 and GSTT1 genetic polymorphisms were evaluated using a previously described multiplex PCR technique[28]. GSTP1 polymorphism was genotyped by the 5' nuclease assay (TaqMan) using the ABI Prism 7900HT Sequence Detection System (Applied Biosystems, Foster City, CA). The primers, probes, and reaction conditions are available upon request. Genotyping for GSTT1 and GSTM1 was completed for 1062 subjects, and genotyping for GSTP1 was completed for 1101 subjects. Laboratory personnel were blinded to case status, and a random $5 \%$ of the samples were repeated to validate genotyping procedures. Two authors independently reviewed all results with $100 \%$ concordance.

\section{Statistical analysis}

Analysis was restricted to subjects who reported using the same well greater than 6 months to minimize potential for temporal variability in well arsenic concentration. Since subjects were frequency matched by age and sex, these variables were included in all regression models $[29,30]$. Arsenic concentration and volume of liquid consumed per day were not combined as a dose variable, since liquid volume included juice, milk, soup, tea, and water. Data exploration using generalized additive models (GAMs), implemented in $\mathrm{R}$ (version 1.8.1), suggested that the log-odds of case status varied linearly with the arsenic concentration of well water; consequently untransformed arsenic concentration was used as a continuous predictor of case status. The models suggested that the log-odds of case status had a nonmonotonic relationship with BMI; therefore a quadratic term for BMI was included. To facilitate numerical stability, both linear and quadratic terms for BMI were centered at the median BMI value, 19.1. Consolidated categories for educational status and age were established.

Univariate analyses were performed to describe population characteristics and to identify possible data errors and/or outliers. Continuous variables were summarized using means, medians, standard deviations and ranges, while categorical variables were described using percentages. Bivariate analyses (chi-squared tests or t-tests, as appropriate) were conducted explore differences between cases and controls prior to multivariate modeling. The frequency distribution of the GSTT1, and GSTM1 polymorphisms were tested among controls to ensure HardyWeinberg equilibrium. The heterozygote and homozygote variant were not combined for GSTP1.

Multiple unconditional logistic regression was used to evaluate the associations between arsenic exposure in drinking water on case status. Odds Ratios were obtained from the regression models, as were their $95 \%$ confidence intervals. Regression models were fit using Statistical Analysis Systems (SAS Institute Inc, Cary NC) version 8.2.

Two different analyses were done to investigate: 1) the associations of GST polymorphisms with skin lesions, adjusting for well arsenic concentration and 2) the modification of the relationship between well arsenic concentration and skin lesions by GST polymorphisms. The joint effects (interaction) of arsenic exposure and each of the genes were evaluated in additive and multiplicative models. Categorical variables were created for measures of arsenic exposure: drinking water arsenic concentration $<50 \mu \mathrm{g} / \mathrm{l}$ and $\geq 50 \mu \mathrm{g} / \mathrm{l}$. The deletion polymorphisms GSTT1 and GSTM1, were modeled as homozygous wildtype and heterozygotes compared to homozygote null.GSTP1 was modeled to determine whether the heter- 
ozygote variant and the homozygote variant might be associated with risk of developing skin lesions compared to wildtype. Variables were created for each combination of arsenic exposure and genotype, with the reference category being low arsenic exposure and either GSTT1 null, GSTM1 null or GSTP1 wildtype AA. Adjusted ORs and 95\% CIs were evaluated for deviation from the expected null value on the additive or multiplicative scale. Interaction Contrast Ratios (ICR) and Bootstrap Percentile Method 1 (BP1) 95\% CIs were calculated to quantify departure from additivity[31]. Synergy on the additive scale is implied by ICRs greater than zero. ICRs of zero imply no additive effects on the additive scale. Antagonism on the additive scale is implied by ICRs less than zero[32]. To estimate interaction on the multiplicative scale adjusted ORs and 95\% CIs were estimated in separate logistic regression models with interaction terms for each genotype and arsenic exposure as a continuous variable. Likelihood ratio tests were conducted comparing adjusted models with main effects for GSTT1, GSTM1 or GSTP1 and arsenic exposure and an interaction term compared to the same model excluding the interaction term.

Sensitivity analysis was conducted by varying weights of controls selected having a well concentration less than 50 $\mu \mathrm{g} / \mathrm{l}$ in a weighted logistic regression analysis as described previously[33]. Briefly, this method was used to determine whether the percentage of controls selected from suspected high and low arsenic areas impacted the stability of the ORs of all of the covariates in the regression models. The weighting varied between $70 \%-95 \%$ of controls with suspected low exposure $(<50 \mu \mathrm{g}$ As/l) and 30\% $-5 \%$ of controls with suspected high exposure $(\geq 50 \mu \mathrm{g}$ As/ 1). Results can be examined graphically in Figure 1.

\section{Results}

Demographic data are presented in Table 1. Of 592 cases, diffuse melanosis accounted for $31.7 \%$ of the cases $(\mathrm{n}=$ 377), followed by leukomelanosis $(\mathrm{n}=342)$, spotted melanosis $(n=145)$, diffuse keratosis $(n=117)$, spotted keratosis $(n=73)$ and hyperkeratosis $(n=40)$. Subjects often had multiple types of lesions. Cases and controls were not significantly different in terms of age, BMI or gender. Controls reported using their current well for a longer duration $(\mathrm{p}=0.02)$, and, conversely, cases reported a higher frequency of previous well use $(\mathrm{p}=0.007)$. As expected, cases had significantly higher well arsenic concentrations $(\mathrm{p}<0.0001)$. No significant difference in total liquid consumption was observed. A higher proportion of cases reported betel nut use $(p=0.007)$, however there was no significant difference between cases and controls in terms of years of betel nut use $(\mathrm{p}=0.78)$ and number of betel nuts chewed daily $(\mathrm{p}=0.53)$. A higher proportion of cases reported chewing tobacco use ( $p<0.0001)$, however there was no difference in years of chewing tobacco use. Conversely, a higher proportion of controls reported current cigarette use $(\mathrm{p}=0.03)$ and ever having smoked ( $\mathrm{p}$ $=0.0007)$. Educational status was not significantly different between cases and controls. Table 1 shows the genotypes frequencies for GSTM1 and GSTT1 and allele frequencies for GSTP1 among cases and control subjects. The crude frequencies of the GST SNPs were not significantly different between cases and controls.

The main effects for each genotype on skin lesions adjusted for well arsenic concentration was shown in Table 2. The GSTT1 wildtype gene carried a higher risk of skin lesions compared to the null polymorphism (OR = 1.56 (95\%CI 1.10-2.19). Compared to the reference category GSTP1 AA, the GG genotype had a $86 \%$ increase odds of skin lesions (OR $=1.8695 \% \mathrm{CI} 1.15-3.00)$. We were not able to detect a significant association with GSTM1 genotype and skin lesions. All models were adjusted for well As level, L/day of total liquid, previous well use, age, sex, education, BMI, chewing tobacco, betel nut use, and smoking status.

Adjusted ORs for the joint effects of well arsenic exposure and each GST polymorphisms on skin lesions are shown in Table 3. Reference categories were low arsenic exposure and GSTM1 null, GSTT1 null or GSTP1 AA, respectively. When the results were stratified on exposure, individuals with the GSTT1 wildtype had a higher risk of lesions in the low (OR $=1.62,95 \%$ CI 1.06-2.49) exposure group as well as the high exposure group, though the relationship was not significant at the high arsenic exposure level (OR $=1.1595 \%$ CI $0.68-1.94$ ). There is little evidence of effect modification by the GSTM1 genotype. In the low exposure strata, individuals with the GSTP1 GG genotype had a higher risk of skin lesions ( $\mathrm{OR}=2.32,1.31-4.09)$ than those individuals with the $A A$ genotype. In the high exposure strata there was no significant effect of the GSTP1 genotype. When the analysis is stratified by genotype for GSTP1, results were difficult to interpret due to the insufficient numbers in high exposure and GSTP1 GG category. Likelihood Ratio Tests (LRT) were not statistically significant (GSTT1 0.88, GSTM1 0.96, and GSTP1 0.21).

Interaction Contrast Ratios (ICR)s for the joint effects of arsenic exposure and the GST polymorphisms are shown in Tables 3. ICRs were not significant. The results are imprecise and should be interpreted cautiously.

Results of the sensitivity analysis are described in Figure 1. The sensitivity analysis of estimates for skin lesion risk predicted by well arsenic concentration varied with the weighting of controls selected from suspected high and low arsenic areas described previously[33]. As expected, varying the percentage of controls with drinking water As exposure $<50 \mu \mathrm{g} / \mathrm{l}$ did not bias the effect estimates for 

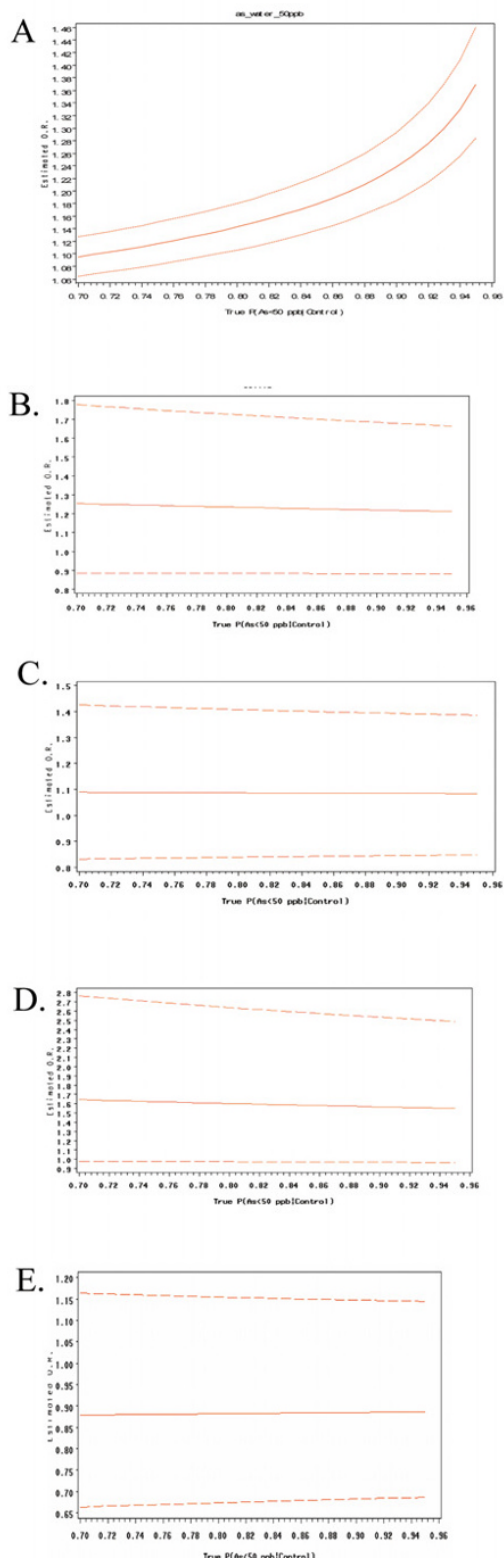

\section{Figure I}

(A) Results from a sensitivity analysis conducted to determine the stability of the main effect of tube well arsenic concentration in $50 \mathrm{ug} / \mathrm{L}$ intervals on the odds ratio for developing skin lesions. (B) Results from a sensitivity analysis conducted to determine the stability of the main effect of GSTTI genotype on the odds ratio for developing skin lesions. (C). Results from a sensitivity analysis conducted to determine the stability of the main effect of GSTMI on the odds for developing skin lesions. (D) Results from a sensitivity analysis conducted to determine the stability of the main effect of GSTPI GG allele on the odds for developing skin lesions. (E) Results from a sensitivity analysis conducted to determine the stability of the main effect of GSTPI AG allele on the odds for developing skin lesions. The sensitivity analysis evaluated the influence of control selection allowing for $\mathbf{7 0 - 9 5 \% ~ o f ~ t h e ~ c o n t r o l s ~ b e i n g ~ s e l e c t e d ~ f r o m ~ t u b e ~ w e l l s ~ c o n t a i n i n g ~ l e s s ~ t h a n ~} 50 \mathrm{ug} / \mathrm{L}$. The black line represents the sampling design employed in this study which assumed that the $80 \%$ of the tube wells in Pabna contained arsenic concentrations below $50 \mathrm{ug} / \mathrm{L}$. As the percentage of controls with arsenic concentrations below $50 \mathrm{ug} / \mathrm{L}$ increases, the OR for skin lesions increases associated with each $50 \mu \mathrm{g} / \mathrm{l}$ increase in tube well arsenic. The $\mathrm{X}$-axis is the percentage of controls selected from areas suspected to have well water arsenic concentration less than $50 \mu \mathrm{g} / \mathrm{l}$. Odds ratios and $95 \% \mathrm{Cl}$ are graphed to show the stability of the effect estimates as the percentage of controls from low exposure areas are varied in the logistic regression model. 
Table I: Characteristics of Skin-Lesion Cases and Population-Based Controls in Pabna, Bangladesh

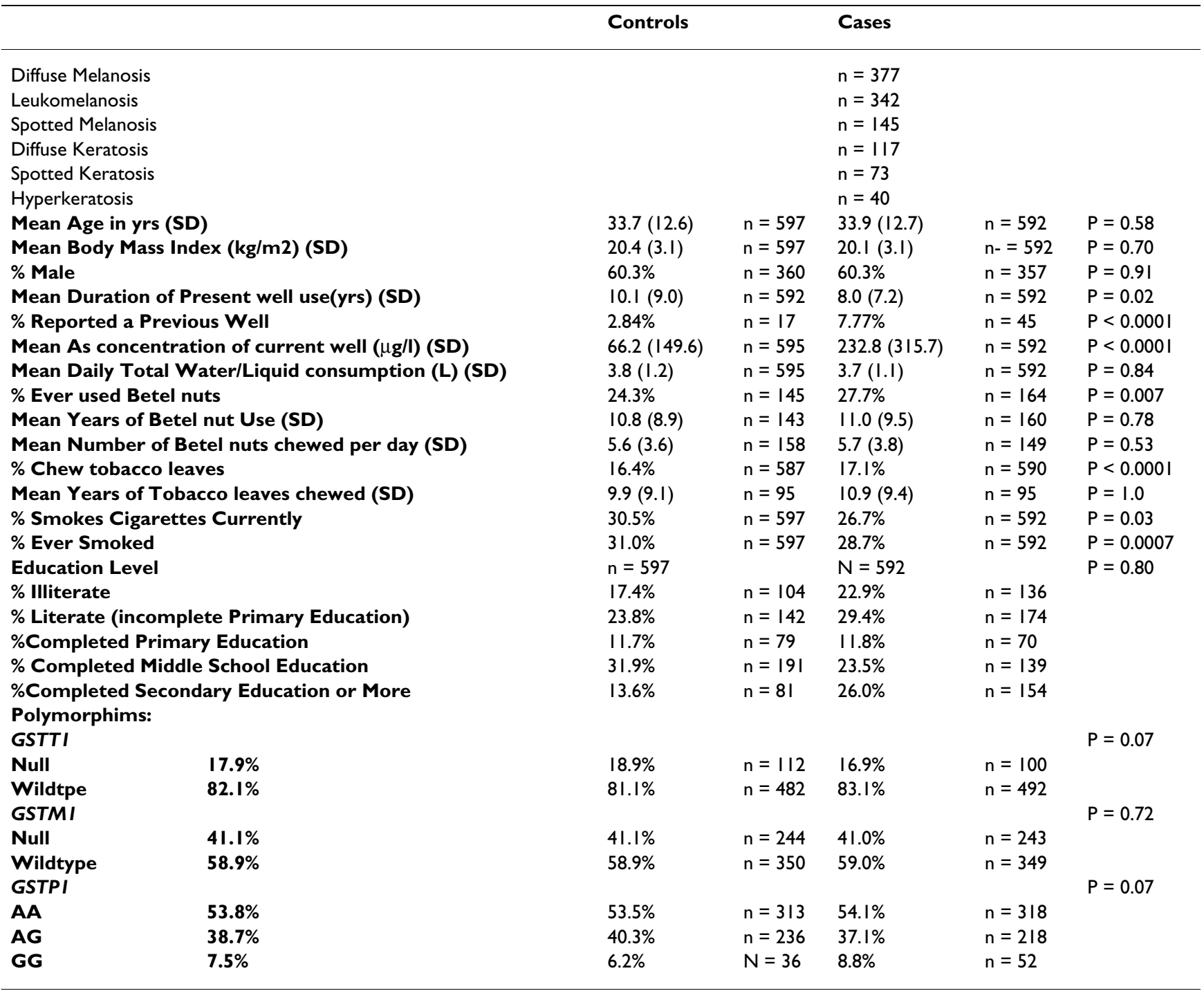

GSTM1, GSTT1, or GSTP1 for risk of skin lesions (Figure $1)$.

\section{Discussion}

We found that GSTT1 wildtype compared to GSTT1 null, and GSTP1 GG compared to GSTP1 AA were associated with an increased odds of arsenic related skin lesions. While the data were suggestive of GST polymorphisms modifying the effect of arsenic exposure levels in drinking water on risk of skin lesions, these effects were not statistically significant.

We found that there was an increased risk of skin lesions among GSTT1 wildtype individuals who produce enzymes that may be associated with increased reduction of glutathione. Previous research has found GST levels increased in arsenic exposed mice and this was thought to be associated with enhanced arsenic efflux by MRP transporters[14]. While there has been no experimental evidence for GSTT1, increased GST activity is associated with enhanced arsenic efflux by MRP transporters, and it is hypothesized that transporters may become saturated at higher exposures. Saturation may result in elevated tissue accumulation of arsenic and increased risk of disease[14]. Furthermore GSTP1 activity may work synergistically with MRP transport of inorganic arsenic as a tri-GSH conjugate[34].

We report for the first time that the GSTP1 GG genotype increases the risk of arsenic related skin lesions in a population based study. In vitro studies have shown that cells that express higher levels of GSTP1 activity were less sensitive to arsenic trioxide induced apoptosis, than cells devoid of GSTP1 activity and expression[35]. GSTP1 has 
Table 2: Crude and Adjusted Odds Ratios and 95\% Cls for Skin Lesions Predicted by GST Polymorphisms.

\begin{tabular}{|c|c|c|c|c|}
\hline \multirow[b]{3}{*}{ Genotype } & \multicolumn{4}{|c|}{ Drinking Water Arsenic Concentrations } \\
\hline & \multicolumn{2}{|c|}{ Crude Model I } & \multicolumn{2}{|c|}{ Adjusted Model I } \\
\hline & OR (95\% Cl) & p-value & OR $(95 \% \mathrm{CI})$ & p-value \\
\hline \multicolumn{5}{|l|}{ GSTPI } \\
\hline$A A$ & 1.0 & & 1.0 & \\
\hline$A G$ & $0.90(0.69-1.17)$ & 0.44 & $0.89(0.68-1.17)$ & 0.41 \\
\hline GG & $1.79(1.12-2.88)$ & 0.02 & $1.86(1.15-3.00)$ & 0.01 \\
\hline GSTTI null & 1.0 & & 1.0 & \\
\hline GSTTI wildtype & $1.52(1.08-2.13)$ & 0.02 & $1.56(1.10-2.19)$ & 0.01 \\
\hline GSTMI null & 1.0 & & 1.0 & \\
\hline GSTMI wildtype & $1.0(0.78-1.29)$ & 0.98 & $0.99(0.77-1.28)$ & 0.95 \\
\hline
\end{tabular}

Crude Models adjusted for As concentration of well or As concentration of well water. Model I adjusted for L/day of water, well As concentration, age, gender, education, BMI, chewing tobacco, betel nut use, and smoking status

been shown to increase growth inhibition of arsenic treated cancer cells and to prevent apoptosis by inhibiting JNK and p38 kinase activity[36]. Our findings are consistent with this, in that those individuals with the polymorphism associated with lower enzyme activity may be more sensitive to the effects of arsenic. However another in vitro study noted that cancer cells were most sensitive to arsenic exposure when GSH was depleted, but that the cellular level of GST- $\pi$ did not affect cellular sensitivity to arsenic[37]. While GSTO1-1 has been shown to reduce methylated arsenic intermediates, in vitro studies have suggested that GSTP1 expression may promote arsenic methylation in cancer cells [38-41]. Further study is needed to clarify the role of the GSTP1 Iso105Val poly- morphism in arsenic metabolism and in the risk of arsenic related skin lesions.

It has been suggested that GST substrates and glutathione conjugates have the ability to induce a variety of Phase II enzymes, so that polymorphisms in GST may influence other chemical defense mechanisms[12]. The role of the GSTP1 Isoleucine (105) to Valine (105) polymorphism remains to be explained [42], as the polymorphism leading to lower enzyme activity appears to be associated with higher risk of skin lesions. In contrast, the expression of glutathione-theta-transferase through GSTT1 wildtype expression appears to be associated with a higher risk of disease. The impact of GSTT1, and GSTP1 polymor-

Table 3: Joint effects of GST genotype and drinking water level of arsenic on Case Status

\begin{tabular}{|c|c|c|c|c|c|c|c|c|c|c|c|}
\hline & \multirow[b]{2}{*}{ As Level of Well } & \multirow[b]{2}{*}{ Controls (N) } & \multirow[b]{2}{*}{ Cases (N) } & \multicolumn{2}{|c|}{ Overall Joint Effects } & \multirow[b]{2}{*}{ ICR } & \multirow[b]{2}{*}{$95 \% \mathrm{CL}$} & \multicolumn{2}{|c|}{$\begin{array}{c}\text { Joint Effects Stratified on } \\
\text { Exposure }\end{array}$} & \multicolumn{2}{|c|}{$\begin{array}{l}\text { Joint Effects Stratified on } \\
\text { Genotype }\end{array}$} \\
\hline & & & & OR $(95 \% \mathrm{Cl})$ & $\mathrm{p}$-value & & & OR $(95 \% \mathrm{Cl})$ & $\mathrm{p}$-value & OR $(95 \% \mathrm{Cl})$ & $\mathrm{p}$-value \\
\hline \multicolumn{12}{|l|}{ GSTTI } \\
\hline Null & low & 85 & 52 & 1.0 & & & & 1.0 & & 1.0 & \\
\hline Wildtpe & low & 376 & 272 & $1.62(1.06-2.49)$ & 0.03 & & & $1.62(1.06-2.49)$ & 0.03 & 1.0 & \\
\hline null & high & 27 & 48 & $3.16(1.71-5.85)$ & 0.0002 & & & 1.0 & & $3.16(1.71-5.85)$ & 0.0002 \\
\hline \multirow[t]{2}{*}{ Wildtpe } & high & 106 & 222 & $3.64(2.3 \mathrm{I}-5.74)$ & $<0.0001$ & & & $1.15(0.68-1.94)$ & 0.60 & $2.24(1.69-2.98)$ & $<0.0001$ \\
\hline & & & & & & 0.94 & $(-2.08-1.83)$ & & & & \\
\hline \multicolumn{12}{|l|}{ GSTMI } \\
\hline Null & low & 189 & 126 & 1.0 & & & & 1.0 & & 1.0 & \\
\hline Wildtype & low & 272 & 198 & $1.02(0.74-1.40)$ & 0.91 & & & $1.02(0.74-1.40)$ & 0.91 & 1.0 & \\
\hline Null & high & 55 & 117 & $2.62(1.77-3.90)$ & $<0.0001$ & & & 1.0 & & $2.62(1.77-3.90)$ & $<0.0001$ \\
\hline \multirow[t]{2}{*}{ Wildtype } & high & 78 & $15 \mid$ & $2.24(1.56-3.22)$ & $<0.0001$ & & & $0.85(0.57-1.29)$ & 0.85 & $2.20(1.57-3.09)$ & $<0.0001$ \\
\hline & & & & & & 1.02 & $(-2.40-1.57)$ & & & & \\
\hline \multicolumn{12}{|l|}{ GSTPI } \\
\hline $\mathrm{AA}$ & low & 246 & 180 & 1.0 & & & & 1.0 & & 1.0 & \\
\hline AG & low & 184 & 110 & $0.81(0.58-1.14)$ & 0.23 & & & $0.81(0.58-1.14)$ & 0.23 & 1.0 & \\
\hline GG & low & 26 & 32 & $2.32(1.31-4.09)$ & 0.004 & & & $2.32(1.31-4.09)$ & 0.004 & 1.0 & \\
\hline $\mathrm{AA}$ & high & 67 & 138 & $2.27(1.60-3.22)$ & $<0.0001$ & & & 1.0 & & $2.27(1.60-3.22)$ & $<0.0001$ \\
\hline$A G$ & high & 52 & 108 & $2.49(1.69-3.68)$ & $<0.0001$ & 0.85 & $(-2 .|3-1.5|)$ & $1.10(0.72-1.69)$ & 0.67 & $3.06(2.01-4.66)$ & $<0.0001$ \\
\hline GG & high & 10 & 20 & $2.38(1.11-5.13)$ & 0.03 & 1.68 & $(-2.15-1.83)$ & $1.04(0.48-2.31)$ & 0.90 & $1.03(0.4 I-2.55)$ & 0.95 \\
\hline
\end{tabular}

All models adjusted for liters of liquid/day, age, gender, educational status, BMI, chewing tobacco, betel nut use, smoking status, and previous well use 
phisms, arsenic exposure and skin lesions and molecular mechanisms require further study.

Limitations of our study include the possibility of recall bias with regard to reported Liters of liquid consumed per day. Moreover, this measure included water as well as other beverages, resulting in possible exposure misclassification for that variable. As with all sample analysis there is a potential for measurement error. However, rigorous quality control procedures were in place for the analysis of water, as well as for DNA extraction and genotyping. In a previous study in West Bengal India, it was reported by Ghosh et al. that individuals with GSTM1 wildtype had significantly higher risk of arsenic-induced skin lesions (Odds Ratio, 1.73; 95\% confidence interval, 1.24-2.22) [43]. This study did not observe an association between GSTT1 or GSTP1 and skin lesions in an arsenic exposed population. Frequencies of GST polymorphisms were similar between the West Bengal study and our results. Due to a much smaller sample size Ghosh et al may have had limited power to detect associations with GSTT1 and GSTP1. Additionally the West Bengal study had only 22 controls and 33 cases who were homozygote null $(-/-)$, and 156 controls and 211 cases who were $(+/-)$ or $(+,+)$. They may not have had an adequate sample size to detect a significant association for GSTT1. For GSTP1, they had even fewer subjects which would not have allowed the ability to detect an association. In the Pabna population, we reported that individuals with the GG genotype (Val/ Val) had a 1.86 increased odds of skin lesions compared to those individuals with the GSTP1 AA genotype (OR 1.86 (95\%CI 1.15-3.00). Ghosh et al reported having 3 cases and 3 controls with the (Val/Val) or GG genotype so they lacked the power to detect the association[43]. Our results are at odds with this population, however as with all studies of single-nucleotide polymorphisms there may be other polymorphisms that are of importance that are in linkage disequlibrium and that may be responsible for some of the observed effects. It has been hypothesized that GSTP1 activity can compensate for the absence of GSTM1 activity[44]. Our study in Pabna, Bangladesh was an ethnically homogenous population of a much larger sample size than the previous study. Our results were also limited by sample size when analysis was stratified on exposure and genotype for case control status for GSTP1 GG due too few subjects in the high exposure category. However, GSTP1 GG was statistically significant overall for skin lesions, as well as in the low exposure drinking water strata. Despite these limitations, significant differences in risk of skin lesions associated with main effects of GSTT1 and GSTP1 genotypes.

\section{Conclusion}

While we did not detect statistically significant interactions on the multiplicative or additive scale between arsenic level and GSTT1, GSTM1 and GSTP1 polymorphisms, we report that the main effects of GSTT1 wildtype and GSTP1 GG appear to be associated with increased risk of skin lesions. A larger sample size would allow a better investigation of the effect of the GSTP1 polymorphism at higher arsenic exposure. There was no evidence of effect modification of GST polymorphisms and arsenic concentration of drinking water on risk of skin lesions. Further work is required to characterize the potential mechanisms related to arsenic metabolism and GSTT1 and GSTP1 polymorphisms.

\section{Abbreviations}

GST Glutathione S-transferase, GSH Glutathione, As Arsenic, Monomethylarsonic acid MMA (V), Monomethylarsonous Acid MMA (III), Dimethylarsinic acid DMA (V), multidrug resistant protein transporters (MRP), reactive oxygen species (ROS), LRT Likelihood Ratio Test, OR Odds Ratio, Interaction Contrast Ratios (ICR), Body Mass Index (BMI), Deoxyribonucleic acid (DNA), JNK, c-Jun $\mathrm{NH}_{2}$-terminal kinase.

\section{Competing interests}

The author(s) declare that they have no competing interests.

\section{Authors' contributions}

KMM was responsible for preparation of the manuscript, analysis of the data, and was involved in lab work and sample preparation.

LR was responsible for study design, statistical consultation and manuscript editing.

AH was involved in statistical consultation.

PW was involved in statistical consultation and manuscript editing.

DPM was involved in statistical consultation and manuscript editing.

$\mathrm{QQ}, \mathrm{MR}$, and GM were responsible for study coordination in Bangladesh, questionnaire data collection, and collection of samples and data entry.

TS was responsible for exposure methods and editing of manuscript.

EG was responsible for dermatologic consultation regarding skin lesions.

LS was responsible for overseeing and conducting genotyping and ensuring quality of data. 
DCC was the study PI, responsible for study design and management, manuscript editing.

\section{All authors approve of the manuscript.}

\section{Acknowledgements}

This work was supported by grants ESOI I622, ES 05947, and ES 00002 from the National Institutes of Health (NIH). K.M.M. was supported by NIH training grant T32ES 06790 . We gratefully acknowledge the expertise of Dr. Miroslav Styblo and Dr. Richard Wilson; the DCH-Pabna field team for subject recruitment, sample collection and data entry; Janna Frelich for data management and Lucille Pothier for programming assistance; Tap Van Geel in the Harvard Molecular Epidemiology Laboratory; Lia Shimada for her expertise and assistance in Human Subjects approval; and the study participants from Pabna, Bangladesh

\section{References}

I. Ahsan H, Perrin M, Rahman A, Parvez F, Stute M, Zheng Y, Milton AH, Brandt-Rauf $P$, van Geen A, Graziano J: Associations between drinking water and urinary arsenic levels and skin lesions in Bangladesh. J Occup Environ Med 2000, 42(I 2): I I 95-I 20 I.

2. Anawar HM, Akai J, Mostofa KMG, Safiullah S, Tareq SM: Arsenic poisoning in groundwater: Health risk and geochemical sources in Bangladesh. Environment International 2002, 27(7):597-604.

3. Smith $A H$, Lingas EO, Rahman M: Contamination of drinkingwater by arsenic in Bangladesh: a public health emergency. Bull World Health Organ 2000, 78(9): 1093-I I03.

4. Nickson R, McArthur J, Burgess W, Ahmed KM, Ravenscroft P, Rahman M: Arsenic poisoning of Bangladesh groundwater. Nature 1998, 395(6700):338.

5. Harvey CF Swartz, Badruzzaman AB, Keon-Blute N, Yu W, Ali MA, Jay J, Beckie R, Niedan V, Brabander D, Oates PM, Ashfaque KN, Islam $\mathrm{S}$, Hemond HF, Ahmed MF.: Arsenic mobility and groundwater extraction in Bangladesh. Science 2002, 298(5598): $1602-1606$.

6. Tondel M Rahman M, Magnuson A, Chowdhury IA, Faruquee MH, Ahmad SA.: The relationship of arsenic levels in drinking water and the prevalence rate of skin lesions in Bangladesh. Environ Health Perspect 1999, 107(9):727-729.

7. Haque R Mazumder DN, Samanta S, Ghosh N, Kalman D, Smith MM, Mitra S, Santra A, Lahiri S, Das S, De BK, Smith AH.: Arsenic in drinking water and skin lesions: dose-response data from West Bengal, India. Epidemiology 2003, I4(2): I74-I82.

8. Yu RC, Hsu KH, Chen CJ, Froines JR: Arsenic Methylation Capacity and Skin Cancer. 2000, 9(II):1259-1262.

9. Vahter M: Genetic polymorphism in the biotransformation of inorganic arsenic and its role in toxicity. Toxicology Letters 2000 , I | 2-I | 3:209-2 I7.

10. Strange RC, Jones PW, Fryer AA: Glutathione S-transferase: genetics and role in toxicology. Toxicology Letters 2000, I I 2I 1 3:357-363.

II. Chiou HY Hsueh YM, Hsieh LL, Hsu LI, Hsu YH, Hsieh FI, Wei ML, Chen HC, Yang HT, Leu LC, Chu TH, Chen-Wu C, Yang MH, Chen C].: Arsenic methylation capacity, body retention, and null genotypes of glutathione S-transferase MI and TI among current arsenic-exposed residents in Taiwan. Mutat Res 1997, 386(3): 197-207.

12. Hayes J, Pulford DJ: The glutathione S-transferase supergene family: regulation of GST and the contribution of the isoenzymes to cancer chemoprotection and drug resistance. Crit Rev Biochem Mol Biol 1995, 30(6):445-600.

13. Kitchin KT: Recent Advances in Arsenic Carcinogenesis: Modes of Action, Animal Model Systems, and Methylated Arsenic Metabolites. Toxicology and Applied Pharmacology 2001, I72(3):249-26I.

14. Xie Y, Liu J, Liu Y, Klaassen CD, Waalkes MP: Toxicokinetic and genomic analysis of chronic arsenic exposure in multidrugresistance mdrla/lb(-/-) double knockout mice. Mol Cell Biochem 2004, 255(I-2): I I-I8.

15. Kala SV, Neely MW, Kala G, Prater Cl, Atwood DW, Rice JS, Lieberman MW: The MRP2/cMOAT Transporter and Arsenic-Glu- tathione Complex Formation Are Required for Biliary Excretion of Arsenic. 2000, 275(43):33404-33408.

16. Gyurasics A, Varga F, Gregus Z: Glutathione-dependent biliary excretion of arsenic. Biochemical Pharmacology I991, 42(3):465-468.

17. Gregus Z, Gyurasics A: Role of glutathione in the biliary excretion of the arsenical drugs trimelarsan and melarsoprol. Biochemical Pharmacology 2000, 59( I I): 1 375- I 385.

18. Ochi T, Kaise T, Oya-Ohta Y: Glutathione plays different roles in the induction of the cytotoxic effects of inorganic and organic arsenic compounds in cultured BALB/c 3T3 cells. Experientia 1994, 50(2): II5-120.

19. Schuliga M, Chouchane S, Snow ET: Upregulation of GlutathioneRelated Genes and Enzyme Activities in Cultured Human Cells by Sublethal Concentrations of Inorganic Arsenic. 2002, 70(2): $183-192$.

20. Styblo $M$, Thomas DJ: Binding of arsenicals to proteins in an in vitro methylation system. Toxicology and Applied Pharmacology 1997, 147(I): I-8.

21. Coles BF, Kadlubar FF: Detoxification of electrophilic compounds by glutathione S-transferase catalysis: determinants of individual response to chemical carcinogens and chemotherapeutic drugs? Biofactors 2003, I7(I-4): I| $15-130$.

22. Watson MA, Stewart RK, Smith GB, Massey TE, Bell DA: Human glutathione S-transferase $P I$ polymorphisms: relationship to lung tissue enzyme activity and population frequency distribution. 1998, 19(2):275-280.

23. BGS/DPHE: Arsenic contamination of groundwater in Bangladesh.Vol 2. Final Report. Edited by: Kinniburgh DG SPL. Keyworth UK, British Geological Society; 2001.

24. Kinniburgh DG, Kosmus W: Arsenic contamination in groundwater:some analytical consideration. Talanta 2002, 58:165-180.

25. Mazumder DNG, Haque R, Ghosh N, De BK, Santra A, Chakraborty $D$, Smith $A H$ : Arsenic levels in drinking water and the prevalence of skin lesions in West Bengal, India. 1998, 27(5):87|-877.

26. Erickson BE: Field kits fail to provide accurate measure of arsenic in groundwater. Environ Sci Technol 2003, 37(I):35A-38A.

27. USEPA: Method 200.8 Determination of Trace Elements in Waters and Wastes by Inductively Coupled Plasma Mass Spectrometry. Edited by: Agency USEP. Cinncinati, OH ; 1994.

28. Liu G, Miller DP, Zhou W, Thurston SW, Fan R, Xu LL, Lynch TJ, Wain JC, Su L, Christiani DC: Differential Association of the Codon 72 p53 and GSTMI Polymorphisms on Histological Subtype of Non-Small Cell Lung Carcinoma. 200I, 6I(24):87I I-8722.

29. Rothman KJ, Greenland S: Chapter 10 Matching. In Modern Epidemiology Volume 2nd Edition. New York , Lippincott, Williams, \& Wilkins; 1998: I47-161.

30. Rothman KJ, Greenland S: Chapter 2 I Introduction to Regression Modeling. In Modern Epidemiology Volume 2nd Edition. New York, Lippincott, Williams \& Wilkins; 1998.

31. Assmann SF, Hosmer DW, Lemeshow S, Mundt KA: Confidence intervals for measures of interaction. Epidemiology 1996, 7(3):286-290.

32. Li Y, Millikan RC, Bell DA, Cui L, Tse CK, Newman B, Conway K: Polychlorinated biphenyls, cytochrome P450 IAI (CYPIAI) polymorphisms, and breast cancer risk among African American women and white women in North Carolina: a population-based case-control study. Breast Cancer Res 2005, 7(I):RI2-8.

33. McCarty KM Houseman EA, Quamruzzaman Q, Rahman M, Mahiuddin G, Smith T, Ryan L, Christiani DC.: The impact of diet and betel nut use on skin lesions associated with drinking-water arsenic in Pabna, Bangladesh. Environ Health Perspect 2006, I I 4(3):334-340.

34. Leslie EM, Haimeur A, Waalkes MP: Arsenic Transport by the Human Multidrug Resistance Protein I (MRPI/ABCCI): EVIDENCE THAT A TRI-GLUTATHIONE CONJUGATE IS REQUIRED. 2004, 279(3I):32700-32708

35. Zhou L, Jing Y, Styblo M, Chen Z, Waxman S: Glutathione-S-transferase \{pi\} inhibits As2O3-induced apoptosis in lymphoma cells: involvement of hydrogen peroxide catabolism. 2005, 105(3): I I 98- 1203.

36. Zhou L, Jing Y, Styblo M, Chen Z, Waxman S: Glutathione-S-transferase pi inhibits As203-induced apoptosis in lymphoma 
cells: involvement of hydrogen peroxide catabolism. Blood 2005, I05(3): II 198-I203.

37. Yang CH, Kuo ML, Chen JC, Chen YC: Arsenic trioxide sensitivity is associated with low level of glutathione in cancer cells. $\mathrm{Br}$ J Cancer 1999, 8 I(5):769-769.

38. Tanaka-Kagawa T, Jinno H, Hasegawa T, Makino Y, Seko Y, Hanioka $\mathrm{N}$, Ando M: Functional characterization of two variant human GSTO I-Is (Ala I 40Asp and Thr2I7Asn). Biochemical and Biophysical Research Communications 2003, 30I(2):5I6-520.

39. Whitbread AK, Masoumi A, Tetlow N, Schmuck E, Coggan M, Board PG: Characterization of the Omega Class of Glutathione Transferases. In Methods in Enzymology Volume Volume 40I. Academic Press; 2005:78-99.

40. Schmuck EM, Board PG, Whitbread AK, Tetlow N, Cavanaugh JA, Blackburn AC, Masoumi A: Characterization of the monomethylarsonate reductase and dehydroascorbate reductase activities of Omega class glutathione transferase variants: implications for arsenic metabolism and the age-at-onset of Alzheimer's and Parkinson's diseases. Pharmacogenet Genomics 2005, I 5(7):493-50।.

4I. Zakharyan RA SRA Healy SM, Tsaprailis G, Board PG, Liebler DC, Aposhian HV.: Human monomethylarsonic acid (MMA(V)) reductase is a member of the glutathione-S-transferase superfamily. Chem Res Toxicol 200I, I 4(8): I05I-I 057.

42. Liu J, Chen H, Miller DS, Saavedra JE, Keefer LK, Johnson DR, Klaassen CD, Waalkes MP: Overexpression of Glutathione S-Transferase II and Multidrug Resistance Transport Proteins Is Associated with Acquired Tolerance to Inorganic Arsenic. 200I, 60(2):302-309.

43. Ghosh P Basu A, Mahata J, Basu S, Sengupta M, Das JK, Mukherjee A Sarkar AK, Mondal L, Ray K, Giri AK.: Cytogenetic damage and genetic variants in the individuals susceptible to arsenicinduced cancer through drinking water. Int J Cancer 2006, I I 8( I 0):2470-2478.

44. Ryberg D, Skaug V, Hewer A, Phillips DH, Harries LW, Wolf CR, Ogreid D, Ulvik A, Vu P, Haugen A: Genotypes of glutathione transferase $M I$ and $P I$ and their significance for lung DNA adduct levels and cancer risk. 1997, I 8(7): | 285- 289.

Publish with Biomed Central and every scientist can read your work free of charge

"BioMed Central will be the most significant development for disseminating the results of biomedical research in our lifetime. "

Sir Paul Nurse, Cancer Research UK

Your research papers will be:

- available free of charge to the entire biomedical community

- peer reviewed and published immediately upon acceptance

- cited in PubMed and archived on PubMed Central

- yours - you keep the copyright 